\title{
1 Component analysis of bio-asphalt binder using crumb rubber modifier and guayule resin as an innovative asphalt replacer
}

\author{
Ahmed Hemida a,", Magdy Abdelrahman ${ }^{\text {b }}$ \\ ${ }^{\text {a }}$ Ph.D. Candidate, Department of Civil, Architectural, and Environmental Engineering, Missouri University of \\ Science and Technology (Missouri S\&T), Rolla, MO 65409, USA
}

${ }^{\mathrm{b}}$ Missouri Asphalt Pavement Association (MAPA) Endowed Professor, Department of Civil, Architectural, and Environmental Engineering, Missouri University of Science and Technology (Missouri S\&T), Rolla, MO 65409, USA

* Corresponding author.

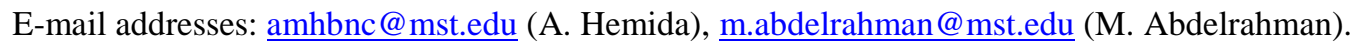

\begin{abstract}
This research seeks to interpret the component analysis of an innovative bio-asphalt binder using guayule resin in addition to crumb rubber modifier (CRM) at high concentrations. Such asphalt modification aims to minimize the dependency on virgin asphalt binder and provide new solutions concerning sustainable, flexible pavement industry. Guayule resin is a promising bioresource for asphalt binder replacement. By now, it could be considered a no value byproduct extracted during the guayule natural rubber production. CRM is a recycled material derived from scrap tires. The provided interpretation could help in understanding the asphalt-rubberguayule interaction mechanism. Fourier transform infrared spectroscopy (FTIR), supported by thermogravimetric analysis (TGA), was used to investigate the component analyses of guayule resin composition, asphalt guayule interaction, and asphalt rubber guayule interaction, compared to corresponding asphalt rubber interaction. Additionally, the rheological properties at elevated temperatures were provided to link the microscale properties with the final product performance. The study clarified the distinct carbon and hydrogen compositional elements of guayule resin. Asphalt and guayule resin have similarities in chemical composition and rheological behavior with temperature susceptibility. The asphalt guayule binder had physical interaction. However, when both interacted with rubber, a chemical interaction was attributed, with no difference in rubber dissolution tendency, in asphalt rubber guayule, compared to asphalt rubber. A bio-binder composed of $62.5 \%$ asphalt, $25 \%$ guayule and $12.5 \%$ CRM had the potential to provide rheological properties better than base asphalt. Such behavior was interpreted by a high release of rubber components.
\end{abstract}

Keywords: Asphalt rubber; Bio-binder; Component analysis; FTIR; Guayule resin; TGA.

\section{Introduction}

Guayule resin is inevitably extracted as a bio-based by-product during the guayule natural rubber (intentionally main guayule shrub derivative) production (Nakayama, 2005). Guayule resin represents $\pm 10 \%$ of the total dry biomass (Rasutis et al., 2015), whereas guayule rubber represents almost the same concentration (Hemida and Abdelrahman, 2018). In addition, other derivatives are extracted from guayule shrub, such as bagasse ( $\pm 80 \%$ of total dry biomass) (Rasutis et al., 2015; Schloman Jr et al., 1986). Guayule commercialization deserves future research investigations since they may enhance the guayule shrub sustainability in terms of economic and environmental concerns (Rasutis et al., 2015). Literature showed that guayule natural rubber is significantly competitive to the current global source of natural rubber (Hevea) (Rasutis et al., 2015). Guayule rubber is a potential domestic natural rubber source of the USA, which could be national security against the 
domination of natural rubber production by Southeast Asia (over $90 \%$ of the global natural rubber production) (Rasutis et al., 2015). The major restriction that most likely stands against the guayule natural rubber production is the economic factors, which could be balanced by getting advantage of other derivatives (bio-based byproducts) (Rasutis et al., 2015).

Guayule resin seems an asphalt-like material: viscoelastic and temperature susceptible (Hemida and Abdelrahman, 2018, 2019a, 2020a, b). However, since the flexible pavement binder is required to have specific grades in order to accomplish the required characterization, the guayule resin as a bioresource may not be desired alone. Hemida and Abdelrahman (Hemida and Abdelrahman, 2018, 2019a, 2020a, b) have previously investigated the influence of adding guayule resin as an asphalt replacer on the asphalt rubber (AR). Guayule resin could provide a benefit as a bio-based by-product; potentially economic, renewable, and environmentally friendly, unlike asphalt cement (Hemida and Abdelrahman, 2018, 2019a, 2020a, b). It has potential to be utilized in the massive flexible pavement industry (Hemida and Abdelrahman, 2018, 2019a). Overall, bio-binders could provide new solutions in terms of sustainability, economics, and environmental concerns (Hemida and Abdelrahman, 2018, 2019a, b). Chemical analysis of the AR has been studied in the literature to a high extent (Nivitha et al., 2016; Ragab, 2016; Ragab and Abdelrahman, 2018; Ragab et al., 2013b). The authors in this study are looking forward to partially replacing AR by $25-75 \%$ guayule resin for sustainable, flexible pavement (Hemida and Abdelrahman, 2019a, 2020a). Asphalt, rubber, and asphalt rubber interaction could help understand the contribution of such a replacer on the final modified asphalt since they have been covered in literature.

The literature clarified that the base asphalt had symmetric and asymmetric $\mathrm{C}-\mathrm{H}$ stretches in $\mathrm{CH}_{2}$ and $\mathrm{CH}_{3}$ at wavenumbers in a range of $3000-2800 \mathrm{~cm}^{-1}$ (Nivitha et al., 2016). It involved four distinct peaks in this range (around $2954 \mathrm{~cm}^{-1}$ (Ragab, 2016; Socrates, 2004), $2924 \mathrm{~cm}^{-1}$ (Ragab, 2016; Zhang et al., 2009), $2870 \mathrm{~cm}^{-1}$ (Ragab, 2016; Socrates, 2004; TFS, 2019), and $2853 \mathrm{~cm}^{-1}$ (Ragab, 2016; Yao et al., 2013; Zhang et al., 2009)). Other peaks were formed around $1458 \mathrm{~cm}^{-1}$ (Ragab, 2016; Yao et al., 2013; Zhang et al., 2009) and $1376 \mathrm{~cm}^{-1}$ (Ragab, 2016; Yao et al., 2013; Zhang et al., 2011) for the same functional group, indicating symmetric and asymmetric bends of $\mathrm{CH}_{3}$ (Bassler, 1981; Smith, 1998). Such functional groups were compatible with the elemental composition of base asphalt (around 80\% carbon and 10\% hydrogen) (Nivitha et al., 2016). Other distinct peaks were observed at $1730 \mathrm{~cm}^{-1}$ and $1032 \mathrm{~cm}^{-1}$ for $\mathrm{C}=\mathrm{O}$ (Ragab, 2016; Yao et al., 2013; Zhang et al., 2009) and $\mathrm{S}=\mathrm{O}$ (Masson et al., 2001; Ragab, 2016; Zhang et al., 2011), respectively. Likewise, the aromatic peak was associated with $\mathrm{C}=\mathrm{C}$ at $1603 \mathrm{~cm}^{-1}$ (Ragab, 2016; Yao et al., 2013; Zhang et al., 2011). Four carbon atoms in a row were observed at $721 \mathrm{~cm}^{-1}$ (Nivitha et al., 2016).

The CRM is composed of rubber/elastomers, carbon black, metallic components, and other additives. Their proportions differ according to the tire type (car, truck/bus, or mix) (Presti, 2013). In other words, the CRM includes natural rubber (cis-isoprene, mainly responsible for elasticity), synthetic rubber (styrene-butadiene rubber [SBR], mainly responsible for thermal stability), metallic elements (containing 15-20\% polar components, highly reactive), and carbon black and textiles (organic fillers) (Nivitha et al., 2016). Though the primary asphalt rubber interaction was physical, the chemical interaction could take place (Nivitha et al., 2016). Normally, it needs higher interaction temperatures to be observed $\left(170-200^{\circ} \mathrm{C}\right)$ since the devulcanization and/or depolymerization may occur causing a rubber dissolution in asphalt (Zanzotto and Kennepohl, 1996). It was rarely seen at lower than this range of interaction temperatures (Nivitha et al., 2016). In literature, the gel permeation chromatography (GPC) showed a reduction in chain length of rubber when interacted with asphalt, indicating its depolymerization in the internal asphalt structure (Billiter et al., 1997; Chipps et al., 2001). In terms of Fourier transform infrared spectroscopy (FTIR) analysis of CRM, the literature claimed that four strong sharp peaks were created for $\mathrm{N}-\mathrm{H}$ stretches between $3500-3000 \mathrm{~cm}^{-1}$ corresponding to amines involved in CRM. The $\mathrm{NH}_{2}$ asymmetric stretch was formed in a wavenumber range of $3500-3420 \mathrm{~cm}^{-1}$. The peak of $\mathrm{NH}_{2}$ symmetric stretch could be found in a wavenumber range of $3500-3420 \mathrm{~cm}^{-1}$. The peak of $\mathrm{NH}_{2}$ scissors stretch could be found at 1637 and $1616 \mathrm{~cm}^{-1}$. Aromatic secondary amine could be formed at $3414 \mathrm{~cm}^{-1}$, and saturated secondary amine or amide could be found at $3238 \mathrm{~cm}^{-1}$ (Nivitha et al., 2016)._On the other hand, the concentration of sulfur in CRM was about 1-2\% depending on the tire type (car or truck/bus) (Presti, 2013; Thodesen et al., 2009). Sulfur in CRM could be attributed to either $\mathrm{C}-\mathrm{S}$ or $\mathrm{S}-\mathrm{S}$ functional groups (Nivitha et 
al., 2016). Since the absorbance of N-H stretch in CRM was significantly high, it was not easy to identify the sulfur bonds as their absorbance was very low in a range of $500-700 \mathrm{~cm}^{-1}$. Likewise, CRM contained aliphatic $\mathrm{C}-\mathrm{H}$ stretch in the region of $3000-2800 \mathrm{~cm}^{-1}$, which had short peaks for the last-mentioned reason. The SBR peak was created at $965 \mathrm{~cm}^{-1}$, indicating $=\mathrm{C}-\mathrm{H}$ in phase out-of-plane bending of trans-1,4-butadiene, and masked by $\mathrm{N}-\mathrm{H}$ scissoring vibration as reported by Nivitha et al. (Nivitha et al., 2016).

Nivitha et al. (Nivitha et al., 2016) investigated the crumb rubber modified asphalt (CRMA) using FTIR, concluding a similarly formed spectrum for both base asphalt and CRMA, except for a few distinct peaks. Only one amine peak was observed at $3300 \mathrm{~cm}^{-1}$, indicating secondary amine/amide. With heating to more than $100^{\circ} \mathrm{C}$, amines reacted with carboxylic acid yielding ammonium carboxylate salt, losing water molecule to produce a secondary amide. Accordingly, it was expected that this could also occur as carboxylic acid was present in asphalt. The SBR peak was formed at $965 \mathrm{~cm}^{-1}$ in CRMA, similar to its formation in CRM (i.e., no observed peak shift) (Nivitha et al., 2016).

In previous work by Hemida and Abdelrahman (Hemida and Abdelrahman, 2019a), a partial asphalt replacement was applied to utilize guayule resin. The CRM was used to compensate for the performance decrease by adding guayule resin to the base asphalt, triggering the same base asphalt performance, at the very least. The CRM was proven to be an asphalt enhancer (Ragab, 2016). In this regard, the literature addressed such enhancement based on interaction parameters (time, temperature, and speed) and material parameters (asphalt grade and CRM source and size). Interaction temperature could be the major parameter influencing the dissolution of CRM into the liquid asphalt (Ghavibazoo et al., 2013b; Ragab et al., 2013a). Researchers have proven that a $190^{\circ} \mathrm{C}$ interaction temperature and a $3000 \mathrm{rpm}$ interaction speed could provide the most enhanced CRMA (Ghavibazoo et al., 2013b; Ragab et al., 2013a). Because of the cross-linked structure of CRM, it is not easy to entirely dissolve in the liquid binder (Zanzotto and Kennepohl, 1996). However, the three-dimension network structure was associated with the CRMA at the recommended interaction parameters above (Ragab et al., 2013b). Three-dimension networking was proven to enhance the binder rheological properties (Ragab et al., 2013b). Therefore, following the literature, the recommended interaction parameters could be a good initiative to apply with the innovative asphalt-rubber-guayule binder (also called bio-binder in this study).

This research mainly seeks to interpret the component analysis of an innovative bio-binder made of guayule resin (promising bioresource for asphalt binder replacement) and crumb rubber modifier. This interpretation will help in understanding the asphalt rubber guayule interaction mechanism. In other words, the authors in this study seek to explore the applicability of using guayule resin as an innovative asphalt replacer from the engineering viewpoint. It is believed that researchers can enhance such an innovative bio-binder in the future based on conceptual research. Literature covered asphalt rubber interaction in a satisfying manner. However, guayule resin still needs to be chemically understood to investigate its chemical influence on asphalt rubber. Accordingly, this paper provides an attempt to analyze such an innovative bio-binder by FTIR analysis of the designated liquid bio-binders, verified by FTIR analysis of extracted CRM from such bio-binders, and supported by some TGA analysis. Additionally, the rheological properties at elevated temperatures were provided to link the microscale properties with the final product performance (Hemida and Abdelrahman, 2019a).

\section{Materials and Methods}

\subsection{Materials}

In this research, a selection of five designated asphalt rubber guayule (AR-BGR) bio-binders was established after multiple attempts of different concentrations of AC, guayule resin made by Bridgestone (BGR), and CRM, as listed in Table 1. The sources of AC, BGR, and CRM were Philips 66 Company, IL; Bridgestone Corp; and Liberty Tire Recycling, respectively. CRM 30-40 (passed mesh \#30 and retained on mesh \#40) was used in this study based on the US standard system (Ghavibazoo et al., 2013a; Zaumanis et al., 
2014). In order to evaluate the impact of guayule resin, such designated bio-binders were compared to ARs by adding extra $\mathrm{AC}$ instead of BGR, same concentration.

The binder codes contained two parts (left and right). The left part was either AR-BGR or AR, and the right part was 25-10, 50-15, 50-20, 75-10, or 75-20. For instance, AR-BGR25-10 denoted 25\% of AR (comprising $10 \%$ of CRM by wt. of AC) and $75 \%$ of BGR. AR25-10 denoted its corresponding AR (i.e., AC replaced the BGR portion). Ultimately, either AR-BGR bio-binder or its corresponding AR binder involved the same CRM concentration in the overall blend. Likewise, binders were designated as WMs and LPs. When relevant, "WM" was enclosed to the binder code (e.g., AR-BGR25-10WM), as was "LP" (e.g., AR-BGR25-10LP).

The blends were created using a high shear mixer with an accurate heating assembly of a heating mantle and a temperature controller. As a part of the preparation process, the as-received guayule resin (coded G) was stirred at $160^{\circ} \mathrm{C}$ for $4 \mathrm{hr}$ with $600 \mathrm{rpm}$ to make sure that no moisture or low molecular weight components were involved (coded G4), as verified in a previous study (Hemida and Abdelrahman, 2019a). The AC was mixed with CRM for $40 \mathrm{~min}$ at $190^{\circ} \mathrm{C}$ and $3000 \mathrm{rpm}$. The G4 was added by decreasing the temperature and speed to $160^{\circ} \mathrm{C}$ and $600 \mathrm{rpm}$, respectively, for $1 \mathrm{hr}$. For ARs, extra AC was added to the initial asphalt rubber blend, instead of guayule resin, following the same interaction parameters.

Table 1. Binder designation and properties.

\begin{tabular}{|c|c|c|c|c|c|c|c|c|c|c|}
\hline \multirow{2}{*}{ Binder } & \multirow{2}{*}{ Binder Code } & \multirow{2}{*}{$\begin{array}{l}\text { CRM\% } \\
\text { by wt. of } \\
\text { AC }\end{array}$} & \multirow[t]{2}{*}{ CRM\% } & \multirow{2}{*}{\multicolumn{2}{|c|}{$\begin{array}{cc}\begin{array}{cc}\text { AC } \\
\%\end{array} & \begin{array}{c}\text { AR } \\
\%\end{array} \\
\text { by wt. of blend }\end{array}$}} & \multirow[t]{2}{*}{$\begin{array}{l}\text { BGR } \\
\%\end{array}$} & \multicolumn{2}{|c|}{$\mathrm{WM}$} & \multicolumn{2}{|c|}{ LP } \\
\hline & & & & & & & $\begin{array}{l}\text { Pass/Fail } \\
\text { Temp }\left[{ }^{\circ} \mathrm{C}\right]\end{array}$ & PG & $\begin{array}{l}\text { Pass/Fail } \\
\text { Temp }\left[{ }^{\circ} \mathrm{C}\right]\end{array}$ & PG \\
\hline Base asphalt & $\mathrm{AC}$ & & & & & & 66 & 64 & 66 & 64 \\
\hline As-received guayule & G & & & & & & 55 & 52 & 55 & 52 \\
\hline 4-hr Heat-Treated BGR & G4 & & & & & & 57 & 52 & 57 & 52 \\
\hline $25 \%(\mathrm{AR} 10 \%)+75 \% \mathrm{BGR}$ & AR-BGR25-10 & 10 & 2.3 & 22.7 & 25 & 75 & 59 & 58 & 59 & 58 \\
\hline $25 \%(\mathrm{AR} 10 \%)+75 \% \mathrm{AC}$ & AR25-10 & 2.4 & 2.3 & 97.7 & 100 & & 68 & 64 & 67 & 64 \\
\hline $50 \%(\mathrm{AR} 15 \%)+50 \% \mathrm{BGR}$ & AR-BGR50-15 & 15 & 6.5 & 43.5 & 50 & 50 & 64 & 64 & 62 & 58 \\
\hline $50 \%(\mathrm{AR} 15 \%)+50 \% \mathrm{AC}$ & AR50-15 & 7 & 6.5 & 93.5 & 100 & & 72 & 70 & 69 & 64 \\
\hline $50 \%($ AR $20 \%)+50 \%$ BGR & AR-BGR50-20 & 20 & 8.3 & 41.7 & 50 & 50 & 65 & 64 & 62 & 58 \\
\hline $50 \%(\mathrm{AR} 20 \%)+50 \% \mathrm{AC}$ & AR50-20 & 9.1 & 8.3 & 91.7 & 100 & & 74 & 70 & 70 & 70 \\
\hline $75 \%(\mathrm{AR} 10 \%)+25 \% \mathrm{BGR}$ & AR-BGR75-10 & 10 & 6.8 & 68.2 & 75 & 25 & 67 & 64 & 65 & 64 \\
\hline $75 \%(\mathrm{AR} 10 \%)+25 \% \mathrm{AC}$ & AR75-10 & 7.3 & 6.8 & 93.2 & 100 & & 73 & 70 & 70 & 64 \\
\hline $75 \%(\mathrm{AR} 20 \%)+25 \% \mathrm{BGR}$ & AR-BGR75-20 & 20 & 12.5 & 62.5 & 75 & 25 & 72 & 70 & 68 & 64 \\
\hline $75 \%(\mathrm{AR} 20 \%)+25 \% \mathrm{AC}$ & AR75-20 & 14.3 & 12.5 & 87.5 & 100 & & 80 & 76 & 74 & 70 \\
\hline
\end{tabular}

151

\subsection{Methods}

\subsubsection{Extracted liquid phase and crumb rubber modifier}

In order to study the chemical analysis of AR-BGRs and corresponding ARs by FTIR, the liquid binder was acquired. Mesh \#200 was used to extract the liquid binder at $165^{\circ} \mathrm{C}$ for about $25 \mathrm{~min}$. The extracted liquid binder was kept in a freezer at $-12^{\circ} \mathrm{C}$ to ensure no undesired reaction or aging (Daly et al., 2010; Ghavibazoo and Abdelrahman, 157 2014; Ghavibazoo et al., 2013a).

In order to study the reduction of the dispersed CRM particle radius and the CRM composition analysis by the FTIR, the CRM (particle) residue was extracted. CRM was extracted by dissolving a sample of $10 \pm 2 \mathrm{~g}$ of the binder whole matrix in a 100 gram of trichloroethylene. The solution was filtrated in a mesh \#200 to retain the CRM particle residue and washed by extra clean TCE until it became colorless. The extracted CRM was placed in an oven at $60^{\circ} \mathrm{C}$ to ensure no TCE remaining. A similar dissolution method was applied in literature (Daly et al., 2010; Ghavibazoo and Abdelrahman, 2014; Ghavibazoo et al., 2013a, b) on AR. Likewise, Hemida and Abdelrahman (Hemida and 


\subsubsection{Dynamic shear rheometer}

In terms of Superpave grading system, the high-temperature grade and pass/fail temperature were measured using Anton Paar DSR (MCR302). A gap of $2 \mathrm{~mm}$ was utilized for all CRM-involved binders (Diab and You, 2017; Lee et al., 2008; Shen and Amirkhanian, 2005). Otherwise, a gap of $1 \mathrm{~mm}$ was used for all liquid binders (AASHTO, 2013). AASHTO T315 was followed for all rheological tests (AASHTO, 2013).

\subsubsection{FTIR}

The Nicolet iS50 FTIR was used to study the chemical analysis of guayule resin, original CRM, extracted CRM from AR-BGRs, and their corresponding ARs (same CRM concentration and same interaction parameters), in addition to the liquid binders extracted from AR-BGRs and ARs. In literature, some researchers used the $\mathrm{KBr}$ disks to investigate the modified asphalt samples. However, this method requires a dilution of modified asphalt samples by a solvent such as toluene to get a thin film layer formed between two KPr disks to facilitate the infrared beam in order to penetrate the specimen and detect the functional groups represented by formed peaks at specific wavenumbers (Glaser et al., 2013; Huang et al., 2012; Ragab, 2016). Furthermore, this method affects the original internal structure properties of the modified asphalt. Accordingly, the authors in this research used a method that directly dealt with the original sample (without any solvent interference). This technique was implemented using an FTIR spectrometer equipped with a diamond attenuated total reflection (ATR) sample cell (FTIR-ATR) (Diab and You, 2017). Overall, the FTIR was used by many researchers to investigate CRMA and polymer modified asphalt (PMA) in order to show the solubility (or dissolution) of polymer/rubber components in the liquid binder of the modified asphalt (Deef-Allah et al., 2020; Masson et al., 2001; Nivitha et al., 2016; Zhang et al., 2011). For example, peaks at 966 to $969 \mathrm{~cm}-1$ and $1600 \mathrm{~cm}^{-1}$ were distinct for styrene butadiene styrene (SBS) or styrene-ethylene butadiene styrene (SEBS) (Ragab, 2016).

\subsubsection{TGA}

TGA is the most common thermal analysis technique. Many researchers have used the TGA instrument to analyze the multi-component samples since each component has its decomposition temperature (Deef-Allah et al., 2020; Ragab, 2016; Ragab and Abdelrahman, 2018; Ragab et al., 2013a). A modifier such as CRM could be analyzed by the ramp (conventional) method, as its components are relatively away from each other. It is easy to distinguish them with the ramp method limitations. In this research, the ramp method using TA Q50 TGA was utilized to investigate the CRM dissolution, either original or extracted out of the liquid bio-binder. The literature interpreted the decomposition temperature ranges of CRM components (Hemida and Abdelrahman, 2020b; Ragab, 2016; Ragab et al., 2013a), and divided the CRM decomposition into four regions:

1) 25 to $300^{\circ} \mathrm{C}$ for oily components,

2) $300^{\circ} \mathrm{C}$ to the temperature at the lowest point on the derivative thermo-gravimetric (DTG) curve for natural rubber,

3) the end of second region to $500^{\circ} \mathrm{C}$ for synthetic rubber, and

4) the residue at $500^{\circ} \mathrm{C}$ for filler components (e.g., carbon black).

\section{Results and Discussion}

\subsection{Chemical analysis of guayule resin}

\subsubsection{Review on Chemical components}

Since guayule resin denotes a bio-based byproduct extracted from guayule plant with the major product (guayule natural rubber), its composition is mainly hydrocarbons, as interpreted in the following section (Nakayama, 2005). Such a composition could also be shown by the molecular formulas (MFs) of its chemical components in Figure 1. It is mainly composed of atoms of carbon $(\mathrm{C})$, hydrogen $(\mathrm{H})$, oxygen $(\mathrm{O})$, and nitrogen $(\mathrm{N})$. However, these atoms are 
included in several chemical compounds. Major chemical components and their molecular formulas such as Triterpenes [Argentatin: - $\mathrm{A}\left(\mathrm{C}_{30} \mathrm{H}_{48} \mathrm{O}_{4}\right)$, - $\mathrm{B}\left(\mathrm{C}_{31} \mathrm{H}_{50} \mathrm{O}_{3}\right)$, - $\mathrm{C}\left(\mathrm{C}_{31} \mathrm{H}_{52} \mathrm{O}_{4}\right)$, - $\mathrm{D}\left(\mathrm{C}_{30} \mathrm{H}_{50} \mathrm{O}_{3}\right)$, - $\mathrm{E}\left(\mathrm{C}_{30} \mathrm{H}_{50} \mathrm{O}_{2}\right),-\mathrm{F}\left(\mathrm{C}_{30} \mathrm{H}_{42} \mathrm{O}_{3}\right)$, $-\mathrm{G}\left(\mathrm{C}_{30} \mathrm{H}_{48} \mathrm{O}_{3}\right)$ and $-\mathrm{H}\left(\mathrm{C}_{30} \mathrm{H}_{48} \mathrm{O}_{3}\right)$ ], Sesquiterpenes [Guayulin: - $\mathrm{A}\left(\mathrm{C}_{24} \mathrm{H}_{30} \mathrm{O}_{2}\right)$, -B $\left(\mathrm{C}_{23} \mathrm{H}_{30} \mathrm{O}_{3}\right)$, $-\mathrm{C}\left(\mathrm{C}_{24} \mathrm{H}_{30} \mathrm{O}_{3}\right)$ and -D $\left(\mathrm{C}_{23} \mathrm{H}_{30} \mathrm{O}_{4}\right)$, and Partheniol $\left(\mathrm{C}_{15} \mathrm{H}_{24} \mathrm{O}\right)$ ), and many others are shown in Figure 1 (Nakayama, 2005; NLM, 2019). 2005).

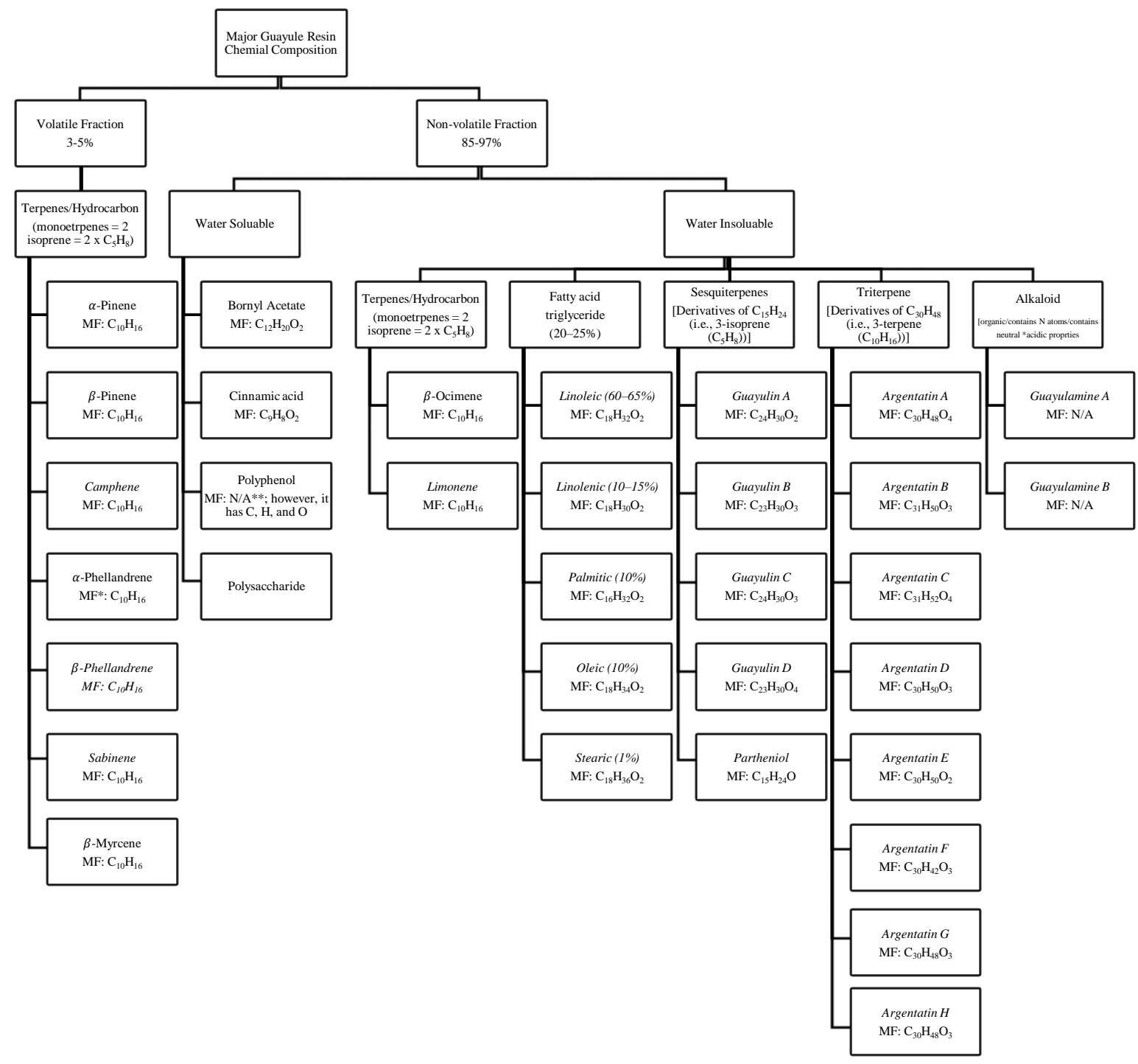

Figure 1. Major chemical components of guayule resin. (MF, molecular formula).

\subsubsection{Chemical bonding}

FTIR spectrum of guayule resin was obtained for its chemical analysis. Guayule resin has several identical peaks similar to the base asphalt, so it is an asphalt-like material (Hemida and Abdelrahman, 2019a). Such identical peaks could be observed in Figure 2. It involved the four distinct peaks of symmetric and asymmetric $\mathrm{C}-\mathrm{H}$ stretches in $\mathrm{CH}_{2}$ and $\mathrm{CH}_{3}$ in the wavenumber range of $3000-2800 \mathrm{~cm}^{-1}$ (aliphatic functional groups). These four peaks were noticed at $2957 \mathrm{~cm}^{-1}\left(\mathrm{CH}_{3}\right.$ asymmetric stretching vibration), $2923 \mathrm{~cm}^{-1}\left(\mathrm{CH}_{2}\right.$ asymmetric stretching vibration), $2868 \mathrm{~cm}^{-1}\left(\mathrm{CH}_{3}\right.$ symmetric stretching vibration), and $2852 \mathrm{~cm}^{-1}\left(\mathrm{CH}_{2}\right.$ symmetric stretching vibration) (Nivitha et al., 2016; TFS, 2019). 
Likewise, $=\mathrm{C}-\mathrm{H}$ aromatic stretching was noticed at $3035 \mathrm{~cm}^{-1}$ with a relatively much lower absorption. Other peaks were formed at 1451 and $1376 \mathrm{~cm}^{-1}$ for the same functional group, indicating asymmetric and symmetric bends of $\mathrm{CH}_{3}$, respectively (Bassler, 1981; Smith, 1998; TFS, 2019). These peaks could clarify the distinct carbon and hydrogen compositional elements of guayule resin (Costa et al., 1992; Nakayama, 2005). Other distinct peaks were observed at $1706 \mathrm{~cm}^{-1}$ and $1031 \mathrm{~cm}^{-1}$ for $\mathrm{C}=\mathrm{O}$ and $\mathrm{S}=\mathrm{O}$, respectively (Petersen, 1986). Likewise, the aromatic peaks were associated with $\mathrm{C}=\mathrm{C}$ at 1606 (Nivitha et al., 2016) and $1512 \mathrm{~cm}^{-1}$ (not observed in base asphalt) (Lionetto et al., 2012). Four carbon atoms in a row were observed at $720 \mathrm{~cm}^{-1}$, indicating $\left(\mathrm{CH}_{2}\right)_{\mathrm{n}}$ rocking absorption (TFS, 2019).

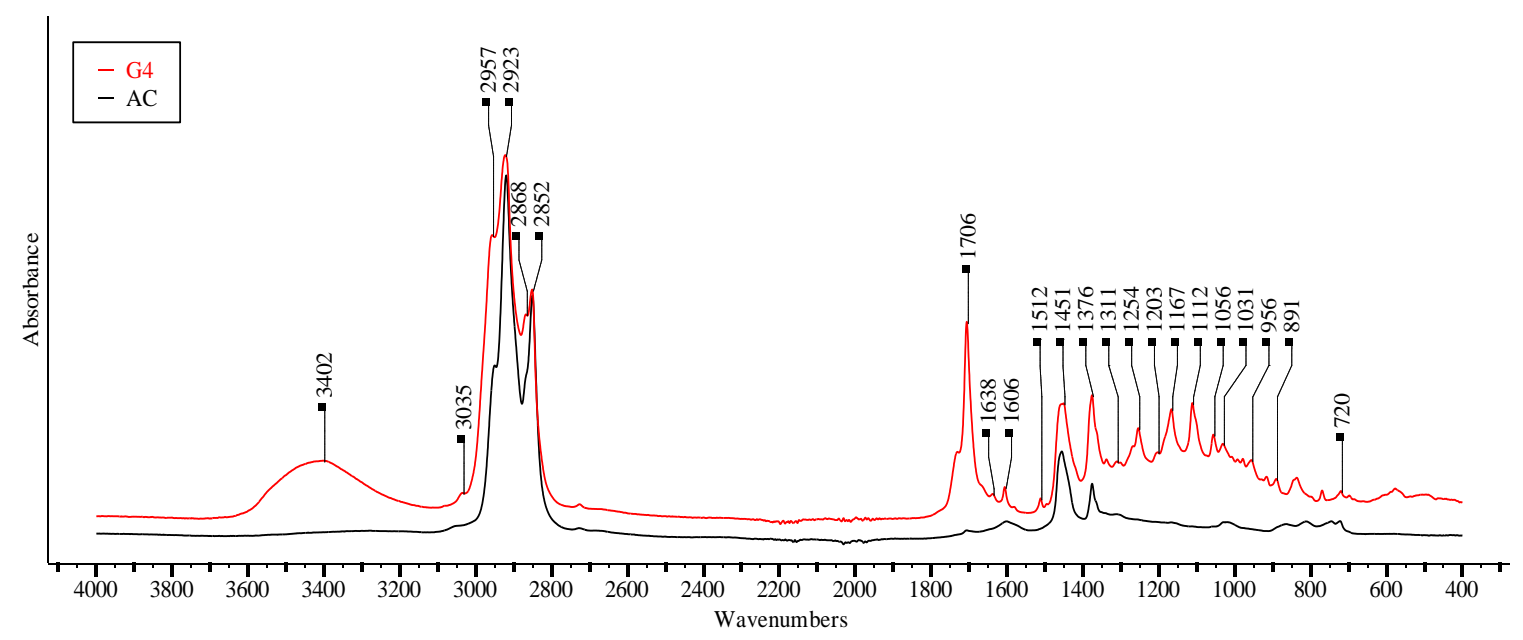

Figure 2. FTIR spectra of G4 and AC $\left(400-4000 \mathrm{~cm}^{-1}\right) .(\mathrm{G} 4,4$ - $\mathrm{hr}$ heat treaded guayule resin; AC, base asphalt (PG64-22)).

Likewise, other peaks were observed for guayule resin. Guayule resin had a peak at $3402 \mathrm{~cm}^{-1}$. This peak was normally associated with broad $-\mathrm{OH}$ stretch (Ghobadi et al., 2018), upon which it may include alcohol. Due to hydrogen bonding, the boiling points of alcohol are much higher than the corresponding alkane with the same number of carbon atoms (TFS, 2019). The peak of $\mathrm{NH}_{2}$ scissors stretch could be found at $1638 \mathrm{~cm}^{-1}$ (Nivitha et al., 2016). Furthermore, the band at 1311 (Smith, 1998; TFS, 2019) and $1254 \mathrm{~cm}^{-1}$ (TFS, 2019) was due to the stretching mode of $\mathrm{C}-\mathrm{O}$ stretching of carboxylic acids. The $-\mathrm{C}-\mathrm{O}$ stretching along with $-\mathrm{OH}$ deformation vibrations may be involved at $1203 \mathrm{~cm}^{-1}$ (phenols), $1167 \mathrm{~cm}^{-1}$ (tertiary alcohols), $1112 \mathrm{~cm}^{-1}$ (secondary alcohols), and $1056 \mathrm{~cm}^{-1}$ (primary alcohols) (TFS, 2019). Peaks from 891 to $956 \mathrm{~cm}^{-1}$ may indicate the presence of $\mathrm{OH}$ deformation in this region (Lionetto et al., 2012).

Ultimately, the above discussion provides an attempt to analyze the bonds linking the guayule resin chemical elements with each other. Some peaks were emphasized with no confusion such as the aliphatic functional groups, observed in a wavenumber range of 3000-2800 $\mathrm{cm}^{-1}$. However, other peaks presented potential of bond formation according to the authors' perspective, supported by literature, as interpreted by guayule resin chemical components in the previous section.

\subsection{Asphalt guayule interaction}

In order to investigate the interaction between asphalt and guayule resin, the FTIR spectrum was obtained for an asphalt guayule blend. The asphalt guayule blend was composed of half of the asphalt and the other half of the guayule resin (the so-called AC-BGR50), mixed at $3000 \mathrm{rpm}$ and $190^{\circ} \mathrm{C}$ for $2 \mathrm{hr}$. As shown in Figure 3a, no new peak or peak shift occurred. However, almost all peaks included in asphalt and guayule resin were formed in the blend. Such pattern could indicate a physical interaction (no chemical interaction between asphalt and guayule resin), which was compatible with Sun et al.'s (Sun et al., 2016) finding, where the FTIR analysis of a blend of asphalt and bio-oil derived from waste cooking oil showed no chemical interaction between bio-oil and asphalt. Furthermore, Hemida and Abdelrahman (Hemida and Abdelrahman, 2020b) proved that there was no liquid phase separation between asphalt and guayule resin after lab-simulated storage. Thus, one could conclude that there was an interaction between asphalt and guayule: physical, not chemical. 

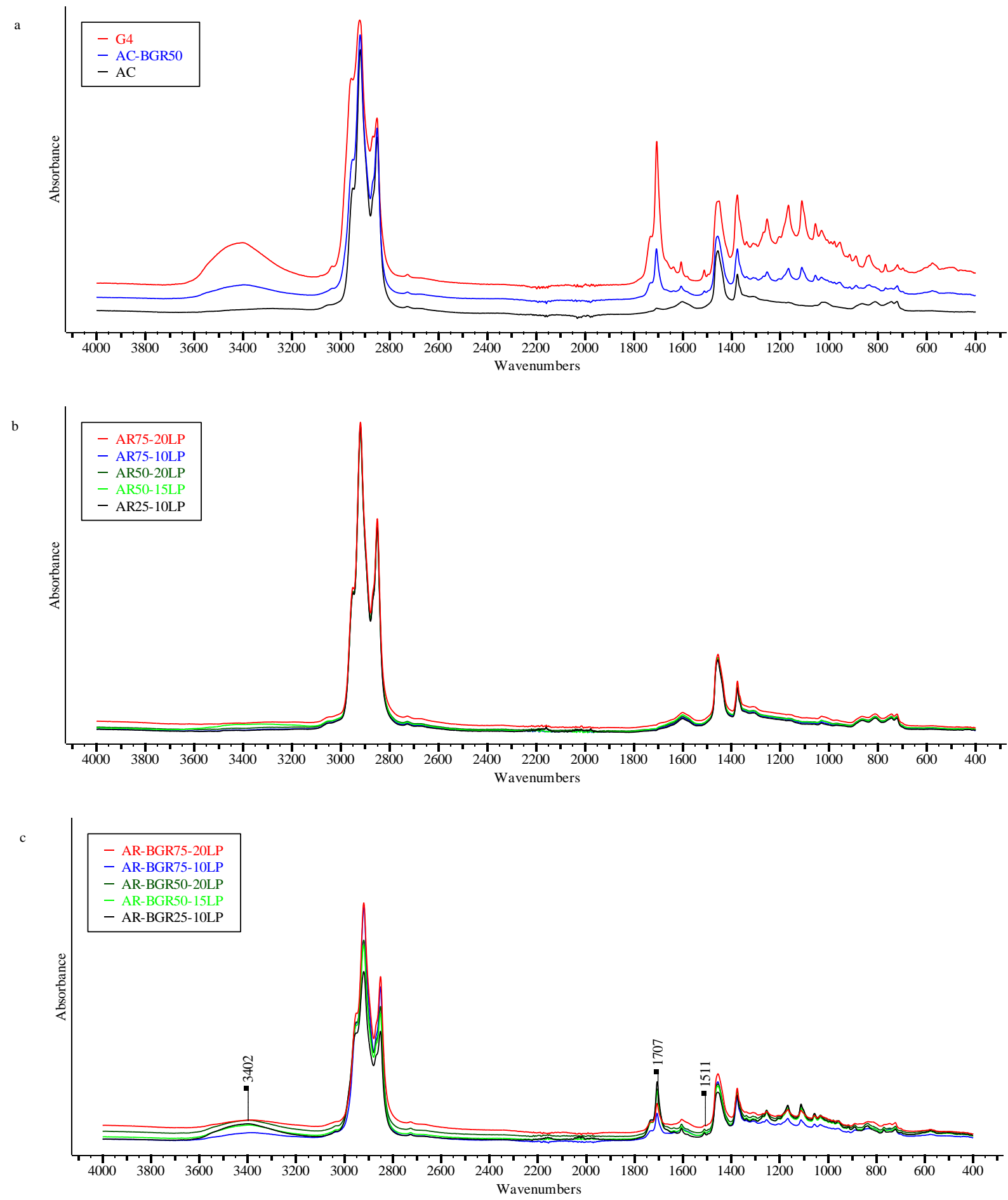

Figure 3. Comparative FTIR spectra of liquid binders (400-4000 $\left.\mathrm{cm}^{-1}\right)$ : (a) Asphalt guayule (AC-BGR), (b) asphalt rubber (AR), and (c) asphalt rubber guayule (AR-BGR). (G4, 4-hr heat treaded guayule resin; AC, base asphalt (PG64-22); AC-BGR50, blend of 50\% AC and $50 \%$ G4; all other codes are for either asphalt-rubber-guayule bio-binders (e.g., AR-BGR25-10, 25\% AR (including 10\% crumb rubber modifier by wt. of AC) and $75 \%$ G4) or its corresponding asphalt rubber (i.e., the same as the bio-binder but with replacing guayule resin by extra asphalt instead, same concentration), e.g., AR25-10; LP, liquid phase/binder). 
The AR25-10, AR50-15, AR50-20, and AR75-10 binders had almost identical spectra (i.e., no distinct peak for one on another), indicating no changes in chemical composition regardless of material concentrations, as shown in Figure 3b. Like AR spectra, one may not notice distinct peak differences among corresponding AR-BGRs (Figure 3c). Nevertheless, the AR-BGRs had multiple peaks, which did not appear in the corresponding AR spectra such as the very polar $(-\mathrm{OH})$ group at $3402 \mathrm{~cm}^{-1}, \mathrm{C}=\mathrm{O}$ at $1707 \mathrm{~cm}^{-1}, \mathrm{C}=\mathrm{C}$ at $1511 \mathrm{~cm}^{-1}$, etc. Such peaks remarkably belonged to the pure guayule resin, as discussed in Section 3.1. On the other hand, one may see the variation of AR-BGR75-20 and AR75-20 spectra compared to other AR-BGRs and ARs, respectively. Such distinction will be clarified hereafter in Section 3.4.

For brevity, Figure 4a shows a portion of the AR75-20 spectrum in comparison with base asphalt and original CRM at distinct peaks. All other ARs yielded a relatively similar scenario. One can observe small peak intensities at 970 and $699 \mathrm{~cm}^{-1}$ for AR75-20. These peaks depict a release of out-of-plane C-H bends of monoalkylated aromatics of polystyrene and trans-alkane of polybutadiene diffused from CRM to liquid asphalt (Ghavibazoo et al., 2013b; Masson et al., 2001; Ragab, 2016). Peaks at 1538, 1398, $461 \mathrm{~cm}^{-1}$ might not significantly appear in the AR75-20 spectrum. However, the CRM residue chemical analysis, discussed in the next section, clarified their transfer from the CRM to the liquid binder. The Peak at $1706 \mathrm{~cm}^{-1}$ was also lost in AR75-20 (Ghavibazoo et al., 2013b). Such lost peak may indicate a swollen CRM particle by one of the asphalt groups, which is the $\mathrm{C}=\mathrm{O}$ functional group.
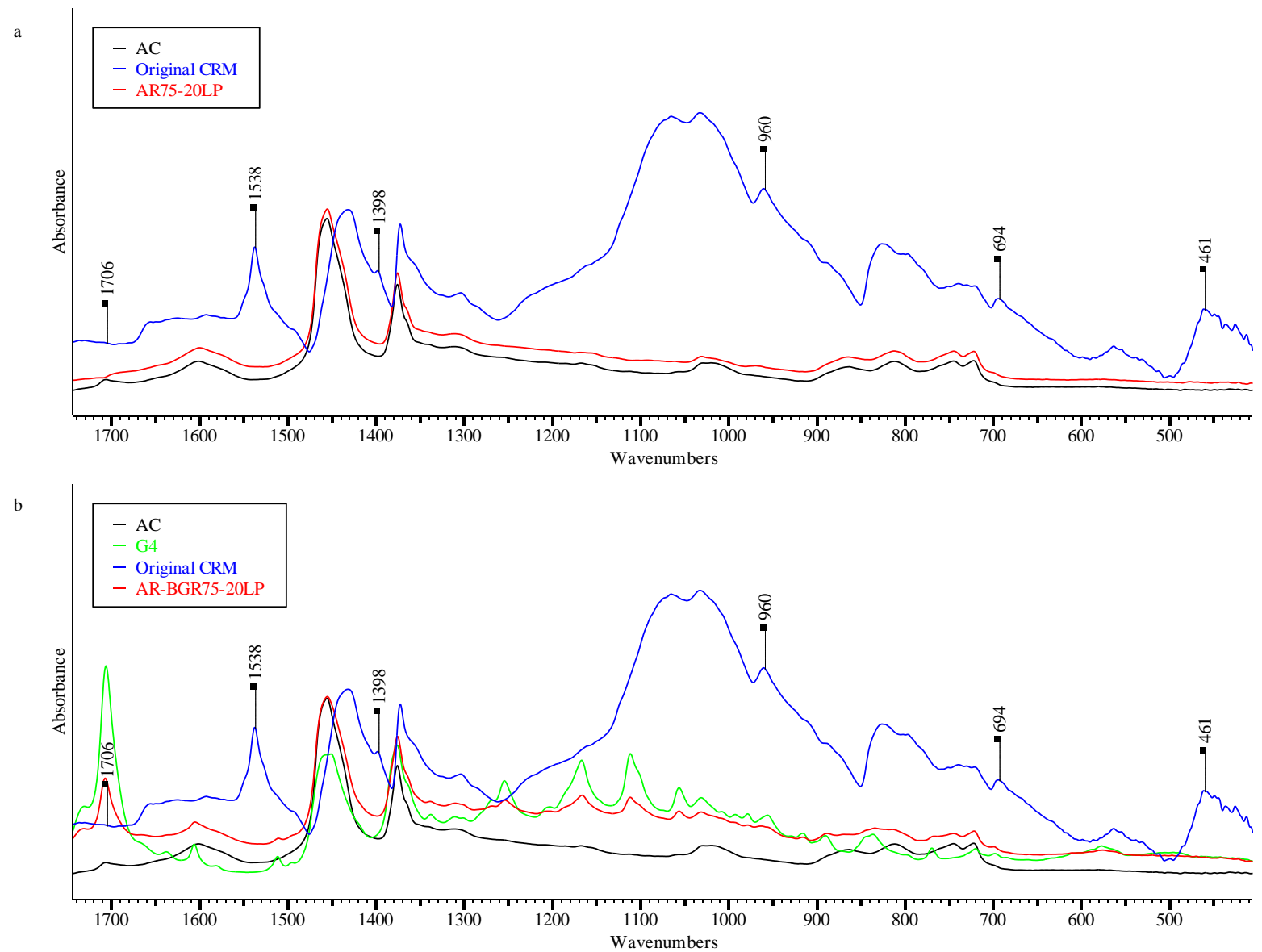

Figure 4. Partial FTIR spectra (400-1750 cm-1): (a) AR75-20LP and (b) AR-BGR75-20LP, in comparison with those of original materials: AC, CRM, and G4. (AC, base asphalt (PG64-22); G4, 4-hr heat treaded guayule resin; CRM, crumb rubber modifier; AR-BGR75-20, 75\% asphalt rubber (including $20 \% \mathrm{CRM}$ by wt. of $\mathrm{AC}$ ) and $25 \% \mathrm{G4}$; AR75-20, the corresponding asphalt rubber by replacing the $25 \% \mathrm{G} 4 \mathrm{by}$ extra $25 \%$ AC instead; LP, liquid phase/binder).

Figure 4b illustrates the distinct peaks investigated for AR-BGR75-20. Due to the high concentration of $\mathrm{C}=\mathrm{O}$ double bond at $1706 \mathrm{~cm}^{-1}$ in guayule resin, a distinct peak was observed in AR-BGR75-20, but with a remarkably lower intensity. Though both guayule resin and original CRM had peak intensities around $960 \mathrm{~cm}^{-1}$, related to 
polybutadiene (Ragab, 2016; Zhang and Hu, 2015), a little-to-no peak was corresponding in AR-BGR75-20 (the same at $690 \mathrm{~cm}^{-1}$, related to polystyrene). The other three peaks at 1538, 1398, and $461 \mathrm{~cm}^{-1}$ in the liquid AR-BGR75-20, like in its corresponding asphalt rubber (AR75-20), were not also clear. However, the CRM residue chemical analysis, in the next section, clarified their transfer from the CRM to the liquid binder.
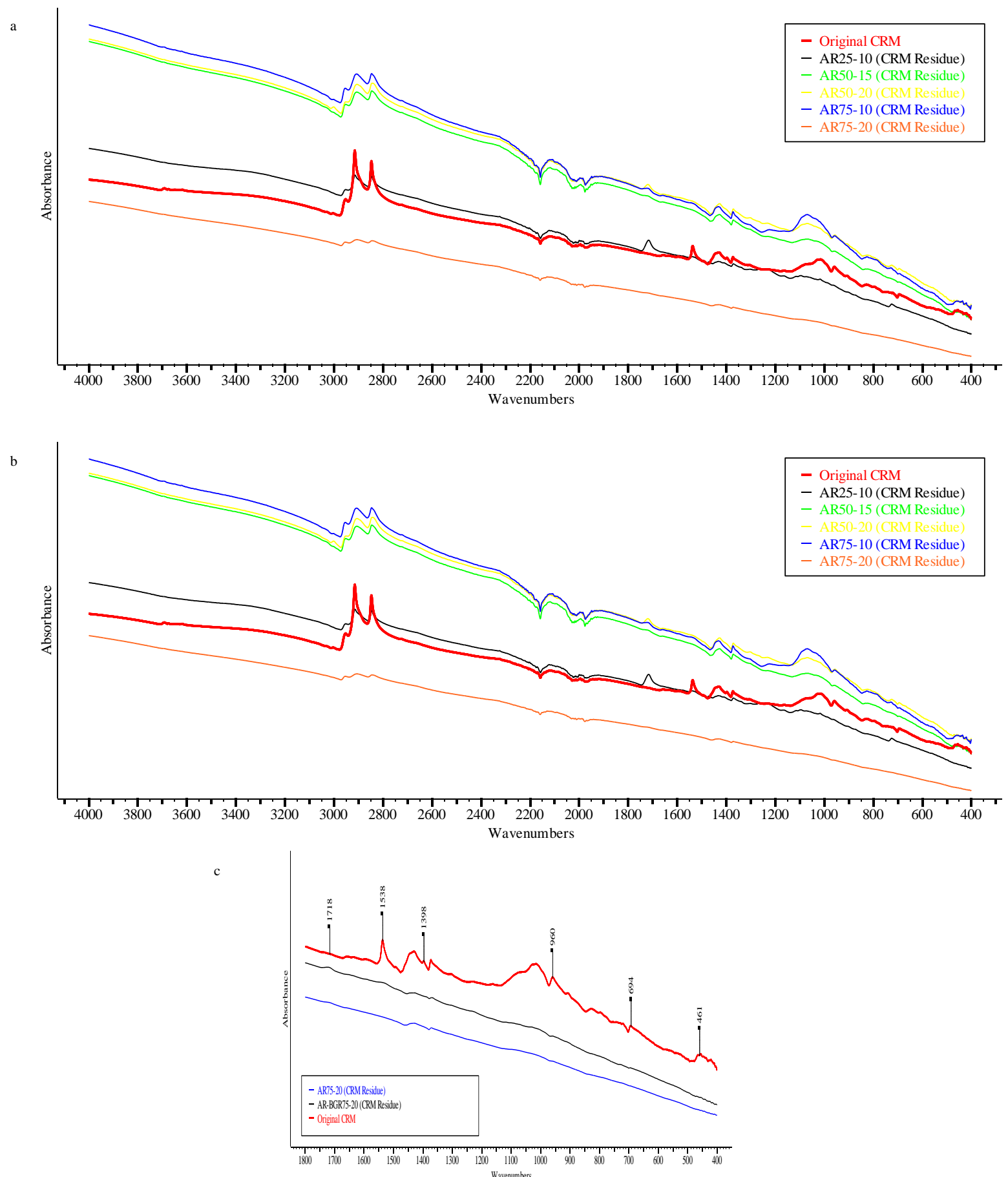

Figure 5. Comparative FTIR spectra of CRM residue: (a) asphalt rubber guayule, (b) asphalt rubber (400-4000 $\left.\mathrm{cm}^{-1}\right)$, and (c) $\mathrm{CRM}$ residue of AR-BGR75-20 and AR75-20, in comparison with the original CRM (400-1800 $\left.\mathbf{~ m}^{-1}\right)$. (CRM, crumb rubber modifier; all other codes represent either the CRM residue of asphalt-rubber-guayule bio-binders (e.g., AR-BGR25-10, 25\% asphalt rubber (including 10\% CRM by wt. of asphalt) and $75 \%$ 4-hr heat-treated guayule resin) or its corresponding asphalt rubber (i.e., the same as asphalt rubber guayule but with replacing guayule by extra asphalt), e.g., AR25-10). 


\subsection{Released component verification by CRM residue Spectra}

FTIR was used to obtain the CRM residue spectra in order to verify the liquid binder chemical analysis. All CRM residue of AR-BGRs had similar spectra. However, a significant difference between the CRM peak intensities before and after interaction (i.e., original CRM vs. residue) was noticed, as shown in Figure 5a. Likewise, the same situation was associated with ARs, as shown in Figure 5b.

For all investigated CRM residue of AR-BGRs and ARs, the peaks almost disappeared at 1398 and $1538 \mathrm{~cm}^{-1}$. Such lost peaks may indicate a devulcanization of $\mathrm{S}-\mathrm{CH}_{\mathrm{n}}$ (Cepeda-Jiménez et al., 2001; Ragab, 2016; Romero-Sánchez et al., 2005) and diffusion of $\mathrm{C}=\mathrm{C}$ in carbon black (Hassan et al., 2013; Ragab, 2016), respectively. One could notice that aliphatic hydrocarbons between 3000 and $2800 \mathrm{~cm}^{-1}$ were affected and their intensities significantly decreased, particularly for AR-BGR75-20 and AR75-20. On the other hand, the FTIR analysis showed a new peak formed at $1718 \mathrm{~cm}^{-1}$ (on average) in CRM residue in variant intensities. Such peak formation may indicate that the swelling of CRM was due to the absorption of light molecular weight aromatics diffused from the liquid binder into CRM residue (Ragab, 2016) (i.e., the $\mathrm{C}=\mathrm{O}$ included in guayule resin and asphalt could be diffused to the CRM residue). It was evident that guayule resin had $\mathrm{C}=\mathrm{O}$ bend with a remarkable intensity, compared to asphalt. Both guayule and asphalt had their original peaks around $1706 \mathrm{~cm}^{-1}$; however, the created peaks were formed around $1718 \mathrm{~cm}^{-1}$.

In particular, CRM residue of either AR-BGR75-20 or AR75-20 remarkably lost peaks (or at least peak intensities significantly decreased) representing a high dissolution of CRM particles into the liquid binder, as verified by the TGA analysis in the next section. The CRM residue had almost no peaks at the wavenumbers of 1538, 1398, 960, 694, and $461 \mathrm{~cm}^{-1}$, as shown in Figure 5c. Additionally, such little-to-no peaks were noticed for all other designated binders. Though a little peak attributed to AR-BGR75-20 and AR75-20 was found around $1718 \mathrm{~cm}^{-1}$, this peak was found to be higher in all other AR-BGRs and ARs.

\subsection{TGA analysis}

For brevity, Figure 6a shows the TGA and DTG curves of original CRM explaining the CRM decomposition, as described in Section 2.2, TGA part. However, the TGA analysis was provided for original CRM and CRM extracted from all AR-BGRs.

The distributions of CRM component proportions before and after its interaction with asphalt guayule (CRM residue) were presented. Figure $\mathbf{6 b}$ illustrates the proportional changes in CRM components extracted from ARBGRs. One may notice that each component had close values regardless of the asphalt, rubber, and guayule concentrations, which consolidated the similarity among the FTIR spectra of the AR-BGRs.

Figure 6c illustrates the proportional changes of CRM components in the presence of the dissolved portion of CRM in the liquid binder (dissolved CRM\%). A significant CRM dissolution was associated with AR-BGR75-20, which was $40 \%$, compared to the rest of AR-BGRs. Such significant dissolution interprets the distinctive FTIR spectrum of AR-BGR75-20 compared to other bio-binders, which had relatively shorter peak intensities. 

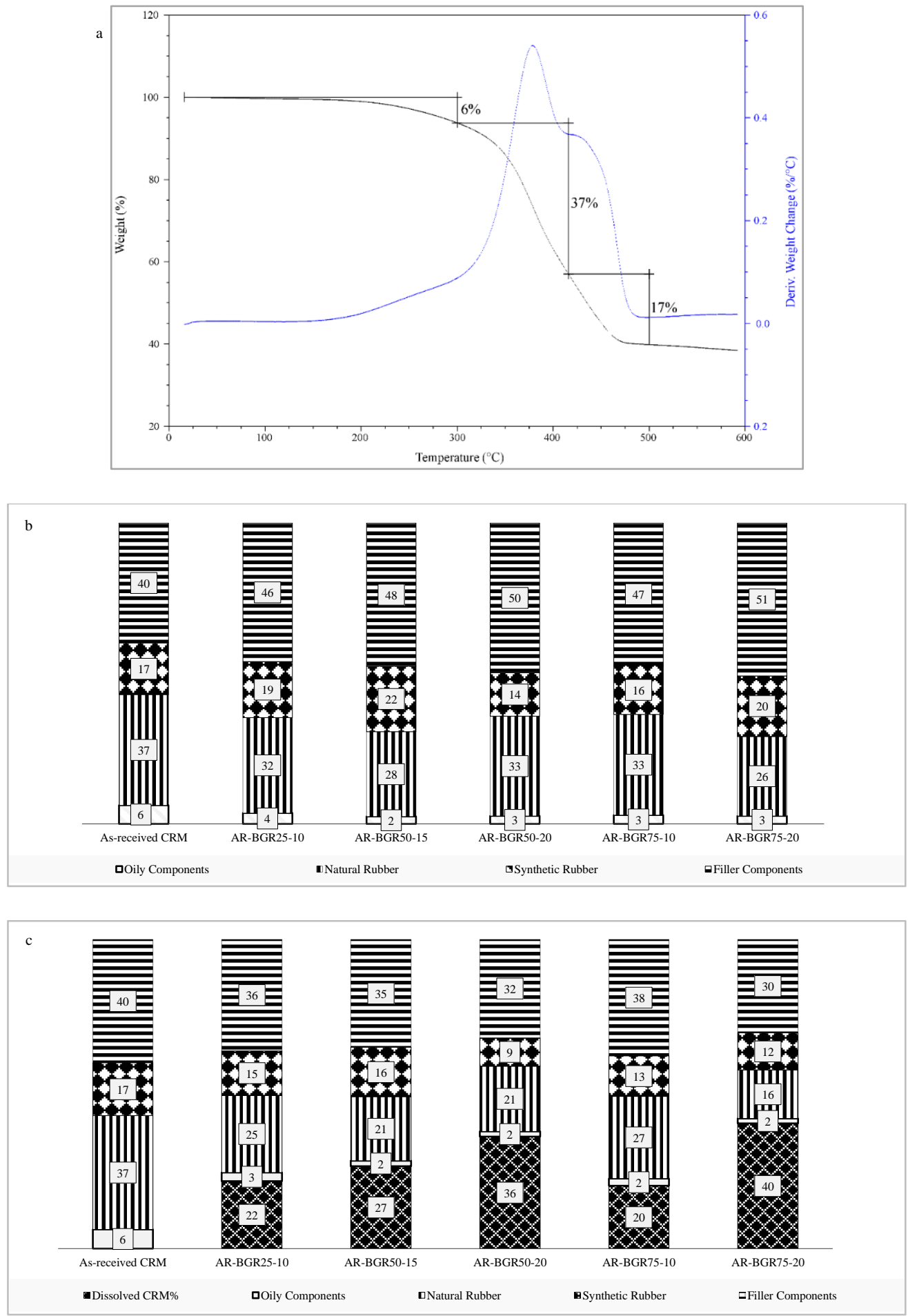

Figure 6. TGA analysis: (a) TGA and DTG curves of as-received CRM, (b) proportional changes in CRM components extracted from asphalt-rubber-guayule binders, and (c) proportional changes of CRM components in the presence of the dissolved portion of CRM for asphalt-rubber-guayule bio-binders. (CRM, crumb rubber modifier; all other codes represent either the CRM residue of asphalt-rubberguayule bio-binders (e.g., AR-BGR25-10, 25\% asphalt rubber (including 10\% CRM by wt. of asphalt) and 75\% 4-hr heat-treated guayule resin) or its corresponding asphalt rubber (i.e., the same as asphalt rubber guayule but with replacing guayule by extra asphalt), e.g., AR25-10). 


\section{Conclusions}

This research provided the component analysis of an innovative bio-asphalt binder made of guayule resin and crumb rubber modifier. The goal was to identify ways to create an innovative asphalt replacer for sustainable pavement using guayule resin. The study confirmed the distinct carbon and hydrogen compositional elements of guayule resin as an asphalt-like material. Asphalt and guayule have similarities in chemical composition and rheological behavior with temperature susceptibility. From analysis, no new peak or peak shift was observed for the asphalt guayule blend. This kind of blending indicated a physical interaction (i.e., no chemical interaction between asphalt and guayule). CRM was similarly released in either asphalt rubber guayule or its corresponding asphalt rubber. In other words, the guayule resin addition did not affect the CRM component dissolution through the liquid binder. However, since the base asphalt did not have the exact chemical structure of guayule resin, the rheological behavior of asphalt rubber guayule was not the same as asphalt rubber, as illustrated in Table 1, which was better for asphalt rubber. FTIR analysis did not show differences between varied concentrations of asphalt, rubber, and guayule, indicating no changes in chemical elements regardless of material concentrations. However, the distinct decrease in peak intensities was associated with the 75\%(AR20\%)+25\%BGR binder, verified by the highest CRM dissolution (about 40\%), illustrated by the TGA analysis. A new peak formed at $1718 \mathrm{~cm}-1$ in CRM residue for all investigated binders in variant intensities. Such a peak formation may indicate that the CRM swelling was caused by the diffusion of some of the liquid binder constituents (asphalt/guayule) into CRM residue. In compliance with a previous rheological study by Hemida and Abdelrahman [5], the relatively better performance of asphalt-rubber-guayule binder, which was associated with the $75 \%(\mathrm{AR} 20 \%)+25 \% \mathrm{BGR}$, was most likely related to such distinct chemical effect. One could conclude that such a binder of $62.5 \%$ of asphalt cement, $12.5 \%$ of crumb rubber modifier, and $25 \%$ of guayule resin has the potential to provide a binder with better high temperature performance than that of the base asphalt (PG64). On the Superpave grading system, such a binder provided a PG70 (as a whole matrix), or at the very least, a PG64 (as a liquid binder).

\section{Acknowledgments}

The authors are very grateful to the Bridgestone Corporation for creating the guayule resin in addition to providing valuable information in this regard. Likewise, special thanks go to Steven Lusher, Ph.D., for his assistance with providing the material samples and information, based on his experience with guayule.

\section{References}

1. AASHTO, 2013. AASHTO T315-12, Standard method of test for determining the rheological properties of asphalt binder using a Dynamic Shear Rheometer (DSR). American Association of State Highway Transportation Officials (AASHTO), Washington, D.C.

2. Bassler, G.C., 1981. Spectrometric identification of organic compounds.

3. Billiter, T., Chun, J., Davison, R., Glover, C., Bullin, J., 1997. Investigation of the curing variables of asphalt-rubber binder. Petroleum science and technology 15(5-6), 445-469.

4. Cepeda-Jiménez, C.M., Pastor-Blas, M.M., Ferrandiz-Gomez, T., Martín-Martínez, J., 2001. Influence of the styrene content of thermoplastic styrene-butadiene rubbers in the effectiveness of the treatment with sulfuric acid. International journal of adhesion and adhesives 21(2), 161-172.

5. Chipps, J.F., Davison, R.R., Glover, C.J., 2001. A model for oxidative aging of rubber-modified asphalts and implications to performance analysis. Energy \& Fuels 15(3), 637-647.

6. Costa, E., Aguado, J., Ovejero, G., Cañizares, P., 1992. Conversion of guayule resin to C1 $\square-\mathrm{C} 10$ hydrocarbons on zeolite based catalysts. Fuel 71(1), 109-113.

7. Daly, W.H., Negulescu, I., Glover, I., 2010. A comparative analysis of modified binders: original asphalts and materials extracted from existing pavements. Louisiana Transportation Research Center.

8. Deef-Allah, E., Abdelrahman, M., Hemida, A., 2020. Improving Asphalt Binder's Elasticity through Controlling the Interaction Parameters between CRM and Asphalt Binder. Advances in Civil Engineering Materials 9(1).

9. Diab, A., You, Z., 2017. Small and large strain rheological characterizations of polymer-and crumb rubber-modified asphalt binders. Construction and Building Materials 144, 168-177.

10. Ghavibazoo, A., Abdelrahman, M., 2014. Effect of Crumb Rubber Dissolution on Low-Temperature Performance and Aging of Asphalt-Rubber Binder. Transportation Research Record 2445(1), 47-55. 
11. Ghavibazoo, A., Abdelrahman, M., Ragab, M., 2013a. Effect of Crumb Rubber Modifier Dissolution on Storage Stability of Crumb Rubber-Modified Asphalt. Transportation research record 2370(1), 109-115.

12. Ghavibazoo, A., Abdelrahman, M., Ragab, M., 2013b. Mechanism of Crumb Rubber Modifier Dissolution into Asphalt Matrix and Its Effect on Final Physical Properties of Crumb Rubber-Modified Binder. Transportation research record 2370(1), 92101.

13. Ghobadi, M., Gharabaghi, M., Abdollahi, H., Boroumand, Z., Moradian, M., 2018. MnFe2O4-graphene oxide magnetic nanoparticles as a high-performance adsorbent for rare earth elements: Synthesis, isotherms, kinetics, thermodynamics and desorption. Journal of hazardous materials 351, 308-316.

14. Glaser, R.R., Schabron, J.F., Turner, T.F., Planche, J.-P., Salmans, S.L., Loveridge, J.L., 2013. Low-temperature oxidation kinetics of asphalt binders. Transportation research record 2370(1), 63-68.

15. Hassan, M.M., Badway, N.A., Elnaggar, M.Y., Hegazy, E.-S.A., 2013. Thermo-mechanical properties of devulcanized rubber/high crystalline polypropylene blends modified by ionizing radiation. Journal of Industrial and Engineering Chemistry 19(4), 1241-1250.

16. Hemida, A., Abdelrahman, M., 2018. A Threshold to Utilize Guayule Resin as a New Binder in Flexible Pavement Industry. International Journal of Engineering Research and Applications 8(12), 83-94.

17. Hemida, A., Abdelrahman, M., 2019a. Influence of Guayule Resin as a Bio-Based Additive on Asphalt-Rubber Binder at Elevated Temperatures. Recycling 4(3), 38.

18. Hemida, A., Abdelrahman, M., 2019b. Review on Rheological Characterization of Bio-Oils/Bio-Binders and their Applicability in the Flexible Pavement Industry. International Journal of Civil Engineering and Technology 10(12), 395-405.

19. Hemida, A., Abdelrahman, M., 2020a. Effect of Guayule Resin as a Bio-Based Additive on Storage Stability and Liquid Phase Separation of Asphalt-Rubber Binder, The 99th Annual Meeting of the Transportation Research Board. Washington, DC.

20. Hemida, A., Abdelrahman, M., 2020b. Monitoring separation tendency of partial asphalt replacement by crumb rubber modifier and guayule resin. Construction and Building Materials 251, 118967.

21. Huang, S.-C., Glaser, R., Turner, F., 2012. Impact of water on asphalt aging: Chemical aging kinetic study. Transportation research record 2293(1), 63-72.

22. Lee, S.-J., Amirkhanian, S.N., Shatanawi, K., Kim, K.W., 2008. Short-term aging characterization of asphalt binders using gel permeation chromatography and selected Superpave binder tests. Construction and Building Materials 22(11), 2220-2227.

23. Lionetto, F., Del Sole, R., Cannoletta, D., Vasapollo, G., Maffezzoli, A., 2012. Monitoring wood degradation during weathering by cellulose crystallinity. Materials 5(10), 1910-1922.

24. Masson, J.F., Pelletier, L., Collins, P., 2001. Rapid FTIR method for quantification of styrene-butadiene type copolymers in bitumen. Journal of Applied Polymer Science 79(6), 1034-1041.

25. Nakayama, F., 2005. Guayule future development. Industrial Crops and Products 22(1), 3-13.

26. Nivitha, M., Prasad, E., Krishnan, J., 2016. Ageing in modified bitumen using FTIR spectroscopy. International Journal of Pavement Engineering 17(7), 565-577.

27. NLM, 2019. PubChem. https://pubchem.ncbi.nlm.nih.gov/. (Accessed Sep 13, 2019.

28. Petersen, J.C., 1986. Quantitative functional group analysis of asphalts using differential infrared spectrometry and selective chemical reactions--theory and application. Transportation Research Record(1096).

29. Presti, D.L., 2013. Recycled tyre rubber modified bitumens for road asphalt mixtures: A literature review. Construction and Building Materials 49, 863-881.

30. Ragab, M., 2016. Enhancing the Performance of Crumb Rubber Modified Asphalt through Controlling the Internal Network Structure Developed. North Dakota State University.

31. Ragab, M., Abdelrahman, M., 2018. Enhancing the crumb rubber modified asphalt's storage stability through the control of its internal network structure. International Journal of Pavement Research and Technology 11(1), 13-27.

32. Ragab, M., Abdelrahman, M., Ghavibazoo, A., 2013a. New Approach for Selecting Crumb-Rubber-Modified Asphalts for Rutting and Permanent Deformation Resistance. Advances in Civil Engineering Materials 2(1), 360-378.

33. Ragab, M., Abdelrahman, M., Ghavibazoo, A., 2013b. Performance Enhancement of Crumb Rubber-Modified Asphalts through Control of the Developed Internal Network Structure. Transportation research record 2371(1), 96-104.

34. Rasutis, D., Soratana, K., McMahan, C., Landis, A.E., 2015. A sustainability review of domestic rubber from the guayule plant. Industrial Crops and Products 70, 383-394.

35. Romero-Sánchez, M.D., Pastor-Blas, M.M., Martín-Martínez, J.M., Walzak, M., 2005. Addition of ozone in the UV radiation treatment of a synthetic styrene-butadiene-styrene (SBS) rubber. International journal of adhesion and adhesives 25(4), 358370.

36. Schloman Jr, W.W., Garrot Jr, D.J., Ray, D.T., Bennett, D.J., 1986. Seasonal effects on guayule resin composition. Journal of agricultural and food chemistry 34(2), 177-179.

37. Shen, J., Amirkhanian, S., 2005. The influence of crumb rubber modifier (CRM) microstructures on the high temperature properties of CRM binders. The International Journal of Pavement Engineering 6(4), 265-271.

38. Smith, B.C., 1998. Infrared spectral interpretation: a systematic approach. CRC press.

39. Socrates, G., 2004. Infrared and Raman characteristic group frequencies: tables and charts. John Wiley \& Sons.

40. Sun, Z., Yi, J., Huang, Y., Feng, D., Guo, C., 2016. Properties of asphalt binder modified by bio-oil derived from waste cooking oil. Construction and Building Materials 102, 496-504.

41. TFS, 2019. OMNIC Spectra Software. Thermo Fisher Scientific. 
42. Thodesen, C., Shatanawi, K., Amirkhanian, S., 2009. Effect of crumb rubber characteristics on crumb rubber modified (CRM) binder viscosity. Construction and Building Materials 23(1), 295-303.

43. Yao, H., You, Z., Li, L., Goh, S.W., Lee, C.H., Yap, Y.K., Shi, X., 2013. Rheological properties and chemical analysis of nanoclay and carbon microfiber modified asphalt with Fourier transform infrared spectroscopy. Construction and Building Materials 38, 327-337.

44. Zanzotto, L., Kennepohl, G.J., 1996. Development of rubber and asphalt binders by depolymerization and devulcanization of scrap tires in asphalt. Transportation Research Record 1530(1), 51-58.

45. Zaumanis, M., Mallick, R.B., Frank, R., 2014. 100\% recycled hot mix asphalt: A review and analysis. Resources, Conservation and Recycling 92, 230-245.

46. Zhang, B., Xi, M., Zhang, D., Zhang, H., Zhang, B., 2009. The effect of styrene-butadiene-rubber/montmorillonite modification on the characteristics and properties of asphalt. Construction and Building Materials 23(10), 3112-3117.

47. Zhang, F., Hu, C., 2015. The research for structural characteristics and modification mechanism of crumb rubber compound modified asphalts. Construction and Building Materials 76, 330-342.

48. Zhang, F., Yu, J., Han, J., 2011. Effects of thermal oxidative ageing on dynamic viscosity, TG/DTG, DTA and FTIR of SBSand SBS/sulfur-modified asphalts. Construction and Building Materials 25(1), 129-137. 